\title{
HIV treatment as prevention in men who have sex with men: examining the evidence
}

\author{
Patrick O'Byrne RN PhD, Paul MacPherson MD PhD \\ CMAJ Podcasts: author interview at https://soundcloud.com/cmajpodcasts/150605-ana
}

Competing interests: Paul MacPherson has received speaker's honoraria from Johnson \& Johnson and from Merck.

No other competing

interests were declared.

This article has been peer reviewed.

Correspondence to: Patrick O'Byrne, pjobyrne@uottawa.ca

CMAJ 2016. DOI:10.1503 /cmaj.150605
$\mathrm{T}$ The potential for antiretroviral therapy to reduce HIV transmission, a strategy known as "treatment as prevention,"1-4 is important in light of unrelenting HIV transmission. The Public Health Agency of Canada has estimated that the number of new cases of HIV infection in Canada in 2014 was 2570 (range 1950-3200), marginally lower than in previous reports. ${ }^{5}$ Treatment as prevention may be of particular relevance for men who have sex with men (MSM), a group that accounts for more than half of these infections. ${ }^{5} \mathrm{To}$ enable practitioners to discuss treatment as prevention with MSM, we outline here the evidence supporting and undermining this approach. We also discuss HIV transmission cofactors and differences in transmission between randomized controlled trials and population-based studies. A nuanced review of this literature is necessary because research has highlighted that some MSM consider treatment as prevention - in isolation from other prevention strategies - to be more protective than it may actually be. As a consequence, practitioners must be able to provide factual information about treatment as prevention on the basis of what is known, including the points that most relevant data arise from samples of heterosexual couples and that treatment as prevention is usually studied as one component of a combination prevention strategy. Importantly, although treatment as prevention could include all strategies that use antiretroviral

\section{KEY POINTS}

- Notwithstanding broad availability of HIV treatment for people living with HIV, the incidence of HIV infection among men who have sex with men continues to climb in Canada and other developing countries.

- In randomized controlled trials, treatment as prevention has significantly prevented onward HIV transmission, but observational studies of clinical practice have not consistently replicated these findings.

- Treatment as prevention appears to most consistently prevent onward HIV transmission when used in combination with other prevention strategies.

- Treatment as prevention appears to function most effectively when clinicians engage patients in monitoring for consistent medication usage and for virologic suppression or resistance, provide support for medication use and work to address possible barriers to care. medications to prevent HIV transmission, here we use the term to refer to use of these medications by people in whom HIV infection has been diagnosed and the effect of such therapy on HIV transmission to sexual partners. We do not discuss the use of antiretroviral medication by HIV-negative people (e.g., as pre- or post-exposure prophylaxis).

\section{What evidence supports HIV treatment as prevention?}

The relation between plasma HIV viral load and HIV transmission among individuals not receiving antiretroviral therapy has been recognized for some time. ${ }^{6,7}$ More recent studies have extended these findings to HIV-positive individuals receiving antiretroviral therapy. In a study published in 2010, researchers following a prospective cohort of 3381 serodiscordant heterosexual couples in Africa documented 103 phylogenetically linked cases of seroconversion. ${ }^{8}$ Only one of these transmission events occurred within a couple in which the HIV-positive partner was receiving antiretroviral therapy. ${ }^{8}$ The authors concluded that "[antiretroviral therapy] use by HIV-1 infected participants was associated with a $92 \%$ reduction in risk of transmission." ${ }^{\circ}$

To clarify the relation between antiretroviral therapy and HIV transmission, Cohen and colleagues ${ }^{9}$ undertook a randomized controlled trial (known as HPTN052) involving 1763 serodiscordant couples (97\% heterosexual). The HIV-positive partner was randomly assigned to start antiretroviral therapy immediately or to delay treatment until indicated by existing clinical guidelines. In both study arms, participants were followed monthly for three months and quarterly thereafter. Importantly, 96\% of participants in both groups reported condom use during all sexual contacts. In total, 27 phylogenetically linked HIV transmissions occurred: 1 in the group with immediate antiretroviral therapy and 26 in the delayed-treatment group (with all transmissions occurring before initiation of antiretroviral therapy). ${ }^{9}$ These data suggest that, 
among heterosexual people who consistently used condoms, the addition of antiretroviral therapy further reduced HIV transmission by about $96 \%$. An important caveat to this study is that it examined the effect of antiretroviral therapy on HIV transmission in the context of consistent condom use, not the effect of treatment alone. Given that it is often the latter issue on which patients seek guidance, it is important to keep in mind that, among all published studies on treatment as prevention, there have been only " 330 couple-years when condoms were not being used."10

The Partner Study, currently underway, expands on HPTN052 and was designed to address perhaps more "real-world" questions. ${ }^{11}$ The study involves 1110 serodiscordant couples (40\% MSM) who engage in unprotected sex at least some of the time, with the HIV-positive partner receiving antiretroviral therapy and having a plasma viral load less than 200 copies $/ \mathrm{mL}$. A recent interim analysis of a subset of 767 couples showed no phylogenetically linked HIV transmissions. ${ }^{11}$ Notably, 343 couples were excluded from the interim analysis because data were missing ( $71 \%$ of exclusions), the HIVpositive partner's plasma viral load had increased to more than 200 copies $/ \mathrm{mL}$ (16\%), HIV test results were not available (5\%), there had been no sexual contact between the partners $(3 \%)$, or the HIV-negative partner opted to use pre- or post-exposure prophylaxis (3\%). Data are currently not available about HIV transmissions among the excluded participants. ${ }^{11}$

\section{Does all evidence support treatment as prevention?}

Not all research has found that antiretroviral therapy reduces HIV transmission. In a retrospective study of 1927 serodiscordant heterosexual couples with 84 cases of seroconversion, conducted in rural China, Lu and colleagues ${ }^{12}$ found no "statistical difference in the seroconversion rates between those couples who had a spouse on ART [antiretroviral therapy] (transmission in 4.8\% of couples), and those couples whose HIV-positive spouse was not on ART (transmission in $3.2 \%$ of couples)" ( $p=0.12)$. The authors concluded that, in the absence of other prevention efforts and intense monitoring to ensure appropriate virologic control and consistent medication usage (as occurs in clinical trials), treatment as prevention may not always prevent HIV transmission. ${ }^{12}$ In their study,${ }^{12}$ no such monitoring occurred, which suggests that the secondary prevention benefits of treatment as prevention may be less likely to materialize in the absence of regular HIV care.
Similarly, in a two-year observational study of 586 serodiscordant heterosexual couples in rural Uganda, where routine monitoring of viral load and CD4+ T cell count was not available, eight cases of seroconversion occurred in the group not receiving antiretroviral therapy and nine in the group receiving therapy. ${ }^{13}$ Reported condom use was $51 \%$ and $67 \%$ among those receiving and not receiving antiretroviral therapy, respectively. ${ }^{13}$ Birungi and colleagues ${ }^{13}$ concluded that a number of factors influence HIV transmission and that, in the absence of routine monitoring and access to HIV care, these factors appear to reduce the prevention benefits of treatment as prevention.

Several methodologically varied epidemiologic analyses have also suggested surprising HIV incidence outcomes among MSM, in spite of treatment as prevention. Specifically, in North America, western Europe and Australia, notwithstanding high levels of HIV-status awareness and increasing coverage for antiretroviral therapy, HIV incidence among MSM has been increasing. ${ }^{14-18}$ In British Columbia, where researchers have stated that treatment as prevention has led to a decrease in total HIV transmissions, ${ }^{1}$ HIV incidence among MSM reportedly "increased by $13 \%$ from 2005 to 2008." Confounding factors affecting HIV transmission, such as Vancouver's safe injection site, needle exchange and peer-based prevention strategies, may have played a role in reducing overall HIV incidence in British Columbia, thus limiting conclusions about the extent to which treatment as prevention can prevent HIV transmission at the population level. ${ }^{4}$ Similar debates have occurred in San Francisco, where some have argued that stabilized rates of HIV transmission among MSM are exclusively the result of antiretroviral therapy, ${ }^{2}$ with others asserting that the relatively stabilized HIV incidence is due to a combination of serosorting and increased HIV-status awareness ${ }^{19}$ (where serosorting is the practice of engaging in sexual activities that can transmit HIV only with partners of concordant HIV status, either as total serosorting [a person has sex only with those whose HIV status is concordant] or as condom serosorting [a person bases the decision to use a condom on concordance or discordance of the other person's HIV status]). As such, when taken together, these ecologic data raise unanswered questions about treatment as prevention.

\section{What factors affect treatment as prevention?}

The variability in data supporting or undermining treatment as prevention is likely rooted in the fact that HIV transmission is simultaneously influ- 
enced by several factors, not all of which may be present (or present to the same degree) in every sexual encounter. Here, we focus on four such factors that have been empirically examined and that relate to clinical practice: differences between plasma and genital HIV viral loads, sexually transmitted infections, access to health care and compensatory decreases in condom use.

First, HIV replication dynamics and antiretroviral drug penetration vary across different body compartments. ${ }^{20-22}$ This variability raises the question of whether an undetectable plasma HIV viral load reliably predicts an undetectable viral load in the genital tract. Simply put, although most published studies have reported a general correlation between viral loads in these two body compartments, ${ }^{23}$ some studies have found discordance in viral loads between blood and genital fluids. Politch and colleagues ${ }^{20}$ analyzed paired blood and semen samples from 101 HIV-positive MSM who were receiving antiretroviral therapy and found that $25 \%$ of those with an undetectable plasma viral load had detectable HIV in semen, ranging from 80 to 2560 copies $/ \mathrm{mL}$. In an analysis of timematched blood and semen samples from 33 men who had undetectable plasma viral loads for more than six months, no urethral sexually transmitted diseases, no comorbidities and consistent antiretroviral therapy use, Lorello and colleagues $^{21}$ found that $6.1 \%$ of participants with undetectable plasma viral loads had detectable semen HIV viral loads above 700 copies $/ \mathrm{mL}$. Similar findings emerged from two studies in France involving 157 and 304 patients, respectively, who were receiving antiretroviral therapy and who had undetectable plasma viral loads, with each study reporting detectable HIV RNA in semen, up to 1475 and 2365 copies $/ \mathrm{mL}$ among $7.6 \%$ and $6.6 \%$ of participants, respectively. ${ }^{24,25}$ Likewise, in a prospective study of 25 HIV-positive men initiating antiretroviral therapy, Sheth and colleagues ${ }^{22}$ detected HIV RNA, ranging from 6672 to 16026 copies $/ \mathrm{mL}$, in $12(48 \%)$ of 25 participants during at least one study visit over 24 weeks, while their plasma viral loads remained undetectable throughout. These data suggest that, although plasma and seminal HIV viral loads may be correlated at the group level, an undetectable viral load in the blood does not always ensure an undetectable viral load in the semen at the individual level, a conclusion that reflects clinical practice. Furthermore, it is noteworthy that, although a lower viral load often corresponds to a decreased probability of transmission, the precise level of seminal viral load needed for efficient HIV transmission has not been empirically determined. Thus, even if the correlation between plasma and seminal fluids were exact, the precise threshold below which transmission would not occur is unknown.

Second, because of $\mathrm{T}$ cell activation, sexually transmitted infections in the genital tract can induce local HIV replication. ${ }^{26,27}$ In one casecontrol study involving $135 \mathrm{HIV}$-positive men not receiving antiretroviral therapy, Cohen and colleague ${ }^{26}$ found that HIV viral loads in semen were eight times higher among men with urethritis than among controls, despite comparable plasma viral loads. More recent studies are conflicting as to whether antiretroviral therapy mitigates the effect of sexually transmitted infections. In their analysis of $36 \mathrm{HIV}$-positive men with symptomatic urethritis who were receiving antiretroviral therapy, Sadiq and colleagues ${ }^{27}$ found that urethral infections were associated with increased seminal HIV viral loads primarily in participants whose plasma viral loads were not controlled by antiretroviral therapy, although two participants did have detectable viral loads in semen but not blood. Likewise, Kelley and colleagues ${ }^{28}$ did not identify any relationship between rectal sexually transmitted infections and increased viral load in rectal secretions among $80 \mathrm{HIV}$-positive men receiving antiretroviral therapy. These results contrast with those of Politch and colleagues, ${ }^{20}$ who found that urethritis and unprotected insertive anal intercourse were independent predictors of seminal HIV detection among men who were receiving effective antiretroviral therapy and who had undetectable plasma viral loads. Notwithstanding these variable findings, no phylogenetically linked HIV transmissions occurred in the Partner Study, ${ }^{11}$ described above, despite $45(16 \%)$ of the 282 MSM couples having a diagnosis of a sexually transmitted infection.

Third, as suggested by the aforementioned studies in rural China ${ }^{12}$ and rural Uganda, ${ }^{13}$ treatment as prevention will function only if people have access to care. When such access is limited, HIV viral loads cannot be monitored, sexually transmitted infections cannot be treated, important psychosocial factors cannot be addressed, and the outcome may be a similar rate of HIV transmission, irrespective of antiretroviral therapy use. ${ }^{12,13}$ This situation highlights how access to care and the ability to address HIV transmission cofactors may potentially strengthen or weaken the extent to which treatment as prevention can prevent HIV transmission. Access to care is also important with regard to consistent and appropriate medication usage. Recent analyses of data from 95 studies ( $n=16907$ patients) in which general medication use was measured through electronic monitoring devices suggest 
that, by day 100 , about $10 \%$ of patients no longer used their medications as prescribed and $20 \%$ had discontinued treatment; by one year, these rates climbed to half not taking their medications as prescribed and $40 \%$ having discontinued therapy. ${ }^{29}$ As such, access to care is not limited to receiving prescriptions but also includes monitoring and support regarding the use of these medications..$^{30}$ This point is important in the interpretation of clinical studies, given that participants in randomized controlled trials are rigorously monitored and counselled, and they receive additional prevention services, the absence of which may undermine the prevention effects of treatment as prevention.

Fourth, compensatory increases in unprotected sex, suggested by recent international studies and reports of increasing bacterial sexually transmitted infections among MSM,${ }^{19}$ could offset the HIV prevention outcomes associated with treatment as prevention. In San Francisco, for example, Katz and colleagues ${ }^{31}$ analyzed elevated HIV incidence in light of increases in self-reported rates of unprotected sex in a multiyear cross-sectional survey ( $n=26176 \mathrm{MSM}$ ). They concluded that "any decrease in per contact risk of HIV transmission due to HAART [highly active antiretroviral therapy] use appears to have been counterbalanced or overwhelmed by increases in the number of unsafe sexual episodes." 31 Although it cannot be known with certainty, this so-called compensatory behavioural disinhibition may relate to beliefs that antiretroviral therapy completely prevents HIV transmission. ${ }^{19}$ Supporting this hypothesis are findings from a metaanalysis of 25 studies by Crepaz and colleagues, ${ }^{32}$ who found that the belief that antiretroviral therapy prevents transmission was associated with a near doubling of unprotected sex.

Taken together, these four factors may explain the current paradoxical situation surrounding treatment as prevention; that is, while empirical evidence from controlled clinical trials suggests that antiretroviral therapy significantly reduces HIV transmission, corresponding data from population-based studies show that, despite increased antiretroviral therapy usage and viral load suppression, there are persistent or increasing rates of HIV transmission among MSM in many locations. Several observational studies have even failed to show the strong anticipated effects of treatment as prevention among MSM. ${ }^{15,17}$ The data informing current understanding about treatment as prevention thus reinforce the idea that HIV transmission is complex and that successful prevention, for people living with HIV, will likely rely more on combined strategies than on antiretroviral medication alone.

\section{Where to go from here?}

To further inform clinical guidelines and recommendations about treatment as prevention (summarized in Table 1), ${ }^{33-39}$ additional research is needed to establish the effects of antiretroviral therapy in situations that more closely resemble realworld sexual practices and clinical practice. Such studies should, for example, involve clinical monitoring of plasma viral loads at frequencies reflecting normal practice (i.e., every three to six months), should include identification of transmissions to and from casual and anonymous sexual partners (not just long-term partners) and should address the impact of untreated sexually transmitted infections (whether asymptomatic or not). Further research should also not assume that all antiretroviral drug combinations yield similar results. The varied pharmacodynamics of these medications (in terms of their half-lives and drug concentrations) in different body compartments may influence results, and data are needed to determine whether certain medications are more or less protective than others.

\section{Conclusion}

According to the available literature, treatment as prevention appears to significantly reduce HIV transmission, albeit with limitations. Indeed, current research seems to highlight that, for treatment as prevention to have its greatest impact, patients must be closely monitored for medication usage, continued suppression of the plasma HIV viral load, timely detection and treatment of sexually transmitted infections, sexual health counselling and, if required, appropriate attention to other health issues. The data further indicate that treatment as prevention works best in combination with other prevention strategies, specifically consistent condom use.

Current data are limited regarding treatment as prevention as an isolated prevention strategy, specifically with respect to prevention outcomes among MSM. Furthermore, many of the data favouring treatment as prevention are based on group-level probabilities, although research has identified individual-level variability in viral load suppression. Notwithstanding these shortcomings, treatment as prevention is clearly an important addition to the armamentarium of HIV prevention strategies. However, practitioners must be cognizant of the aforementioned limitations so they can inform patients of what is actually known, rather than raising false expectations as to the real-world effectiveness of treatment as prevention.

In short, treatment as prevention is an important component of combination prevention and appears 
to work best (and perhaps only) in conjunction with routine clinical care. With an appropriately nuanced appreciation of how and when treatment as prevention appears to work, it is thus possible for this approach to help decrease ongoing HIV transmission, which disproportionately affects MSM.

Table 1: Summary of recommendations for HIV treatment that have implications for treatment as prevention

\begin{tabular}{|c|c|c|}
\hline Organization & $\begin{array}{c}\text { Date } \\
\text { published }\end{array}$ & Recommendations \\
\hline British HIV Association ${ }^{33}$ & $\begin{array}{l}\text { November } \\
2013\end{array}$ & 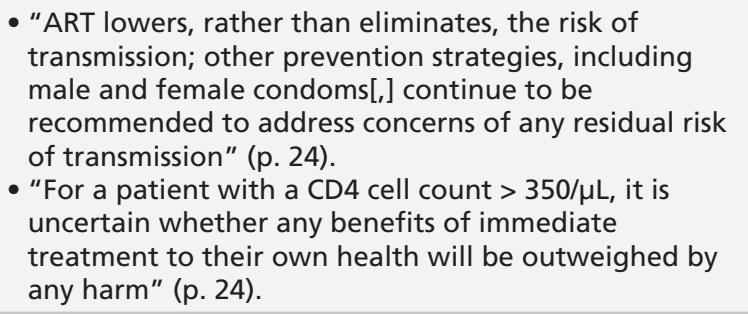 \\
\hline $\begin{array}{l}\text { British Columbia Centre for } \\
\text { Excellence in HIVIAIDS }\end{array}$ & $\begin{array}{l}\text { September } \\
2015\end{array}$ & $\begin{array}{l}\text { "ART is most strongly recommended ... in the following } \\
\text { situations: } \\
\text { - Symptomatic HIV infection ... } \\
\text { - Lower CD4 cell counts } \\
\text { - The HIV-infected member of a serodiscordant couple, } \\
\text { regardless of symptoms or CD4 count, to prevent } \\
\text { transmission to the HIV-uninfected partner" (p. 10). }\end{array}$ \\
\hline $\begin{array}{l}\text { Centers for Disease Control } \\
\text { and Prevention (US) })^{35}\end{array}$ & $\begin{array}{l}\text { December } \\
2014\end{array}$ & $\begin{array}{l}\text { "[R]ecommend ART for all persons with HIV, regardless } \\
\text { of CD4 cell count, to improve their health, prolong their } \\
\text { lives, and reduce their risk of transmitting HIV to } \\
\text { others" (p. 69, emphasis in the original). }\end{array}$ \\
\hline $\begin{array}{l}\text { Commission d'experts } \\
\text { clinique et thérapie VIH et } \\
\text { sida (also known as the } \\
\text { "Swiss Statement") }\end{array}$ & 2008 & $\begin{array}{l}\text { "An HIV-positive individual not suffering from any other } \\
\text { STD and adhering to antiretroviral therapy (ART) with a } \\
\text { completely suppressed viremia ... does not transmit HIV } \\
\text { sexually, i.e., he/she cannot pass on the virus through } \\
\text { sexual contact[,] ... provided that: } \\
\text { - the HIV-positive individual fully complies with the } \\
\text { antiretroviral therapy and is monitored by an } \\
\text { attending physician; } \\
\text { - the viral load ... has been non-detectable for at least } \\
\text { six months (i.e., viremia has been suppressed for at } \\
\text { least six months); } \\
\text { - the HIV-positive individual does not have any other } \\
\text { sexually transmitted disease" (p. 3, emphasis in the } \\
\text { original). }\end{array}$ \\
\hline $\begin{array}{l}\text { International Antiviral } \\
\text { Society }^{37}\end{array}$ & July 2014 & $\begin{array}{l}\text { - "ART is recommended for the treatment of HIV } \\
\text { infection and for the prevention of transmission of } \\
\text { HIV" (p. 412). } \\
\text { "ART is recommended regardless of CD4 cell count" } \\
\text { (p. 412). }\end{array}$ \\
\hline $\begin{array}{l}\text { US Department of Health } \\
\text { and Human Services }{ }^{38}\end{array}$ & April 2015 & $\begin{array}{l}\text { - "ART should be initiated in patients with CD4 counts } \\
\text { [of] } 350 \text { to } 500 \text { cell/mm3" (p. E-3). } \\
\text { - "Recent evidence demonstrating the public health } \\
\text { benefit of earlier initiation of ART in reducing HIV } \\
\text { transmission further supports the strength of this } \\
\text { recommendation" (p. E-3). } \\
\text { - "ART [should] be offered to patients who are at risk of } \\
\text { transmitting HIV to sexual partners" (p. E-11). }\end{array}$ \\
\hline World Health Organization ${ }^{39}$ & June 2013 & $\begin{array}{l}\text { - Initiate antiretroviral medications for persons with } \\
\text { CD4+ cell count } \leq 500 \text { cell/mm } / \mathrm{mm}^{3} \\
\text { - Prioritize antiretroviral medications to persons with } \\
\text { CD4+ counts of } \leq 350 \text { cell/mm } / \mathrm{mm}^{3} \\
\text { "HIV-positive partners with a CD4+ count } \\
\geq 350 \text { cells/mm } / \mathrm{mm}^{3} \text { in serodiscordant couples should be } \\
\text { offered ART to reduce HIV transmission to uninfected } \\
\text { partners" (section } 5.2 .2 \text { ). }\end{array}$ \\
\hline
\end{tabular}




\section{References}

1. Montaner JSG, Lima VD, Barrios R, et al. Association of highly active antiretroviral therapy coverage, population viral load, and yearly new HIV diagnoses in British Columbia, Canada: a population-based study. Lancet 2010;376:532-9.

2. Das M, Lee Chu P, Santos GM, et al. Decreases in community viral load are accompanied by reductions in new HIV infections in San Francisco. PLoS One 2010;5:e11068.

3. Muessig KE, Smith MK, Powers KA, et al. Does ART prevent HIV transmission among MSM? AIDS 2012;26:2267-73.

4. Smith MK, Powers KA, Muessig KE, et al. HIV treatment as prevention: the utility and limitations of ecological observation. PLoS Med 2012;9:e1001260.

5. Summary: estimates of HIV incidence, prevalence and proportion undiagnosed in Canada, 2014. Ottawa: Public Health Agency of Canada; 2015. Available: www.catie.ca/sites/default/files /2014-HIV-Estimates-in-Canada-EN.pdf (accessed 2015 Dec. 10)

6. Quinn TC, Wawer MJ, Sewankambo N, et al. Viral load and heterosexual transmission of human immunodeficiency virus type 1. N Engl J Med 2000;342:921-9.

7. Fideli US, Allen SA, Musonda R, et al. Virologic and immunologic determinants of heterosexual transmission of human immunodeficiency virus type 1 in Africa. AIDS Res Hum Retroviruses 2001:17:901-10.

8. Donnell D, Baeten JM, Kiarie J, et al. Heterosexual HIV-1 transmission after initiation of antiretroviral therapy: a prospective cohort analysis. Lancet 2010;375:2092-8.

9. Cohen MS, Chen YQ, McCauley M, et al. Prevention of HIV-1 infection with early antiretroviral therapy. N Engl J Med 2011;365 493-505.

10. Rodger AJ, Bruun T, Vernazza P, et al. Further research needed to support a policy of antiretroviral therapy as an HIV prevention initiative. Antivir Ther 2013;18:285-7.

11. Rodger AJ, Cambiano V, Bruun T, et al. HIV transmission risk through condomless sex if the HIV positive partner is on suppressive ART: PARTNER study [presentation]. 21st Conference on Retroviruses and Opportunistic Infections; 2014 Mar. 3-6; Boston. Available: www.chip.dk/portals/0/files/CROI_2014_PARTNER slides.pdf (accessed 2014 Jan. 10)

12. Lu W, Zeng G, Luo J, et al. HIV transmission risk among serodiscordant couples: a retrospective study of former plasma donors in Henan, China. J Acquir Immune Defic Syndr 2010;55:232-8.

13. Birungi J, Min JE, Muldoon KA, et al. Lack of effectiveness of antiretroviral therapy in preventing HIV infection in serodiscordant couples in Uganda: an observational study. PLoS One 2015; 10:e0132182.

14. Sullivan PS, Hamouda O, Delpech V, et al. Reemergence of the HIV epidemic among men who have sex with men in North America, western Europe, and Australia, 1996-2005. Ann Epidemiol 2009;19:423-31.

15. Birrell PJ, Gill ON, Delpech VC, et al. HIV incidence in men who have sex with men in England and Wales 2001-10: a nationwide population study. Lancet Infect Dis 2013;13:313-8.

16. Bezemer D, de Wolf F, Boerlijst MC, et al. A resurgent HIV-1 epidemic among men who have sex with men in the era of potent antiretroviral therapy. AIDS 2008;22:1071-7.

17. Phillips AN, Cambiano V, Nakagawa F, et al. Increased HIV incidence in men who have sex with men despite high levels of ART-induced viral suppression: analysis of an extensively documented epidemic. PLoS One 2013;8:e55312.

18. van Sighem A, Vidondo B, Glass TR, et al. Resurgence of HIV infection among men who have sex with men in Switzerland mathematical modelling study. PLoS One 2012;7:e44819.

19. Truong HH, Kellogg T, Klausner JD, et al. Increases in sexually transmitted infections and sexual risk behaviour without a concurrent increase in HIV incidence among men who have sex in men in San Francisco: A suggestion of HIV serosorting? [published erratum in Sex Transm Infect 2007;83:76]. Sex Transm Infect 2006;82:461-6.

20. Politch JA, Mayer KH, Welles SL, et al. Highly active antiretroviral therapy does not completely suppress HIV in semen of sexually active HIV-infected men who have sex with men. AIDS 2012;26:1535-43

21. Lorello G, la Porte C, Zhang G, et al. Discordance in HIV-1 viral loads and antiretroviral drug concentrations comparing semen and blood plasma. HIV Med 2009;10:548-54

22. Sheth PM, Kovacs C, Kemal KS, et al. Persistent HIV RNA shedding in semen despite effective antiretroviral therapy. AIDS 2009;23:2050-4.

23. Vernazza PL, Troiani L, Flepp M, et al. Potent antiretrovira treatment of HIV infection results in suppression of the semina shedding of HIV. The Swiss HIV Cohort Study. AIDS 2000; $14: 117-21$
24. Lambert-Niclot S, Tubiana R, Beaudoux C, et al. Detection of HIV-1 RNA in seminal plasma samples from treated patients with undetectable HIV-1 RNA in blood plasma on a 2002-2011 survey. AIDS 2012;26:971-5.

25. Ghosn J, Leruez-Ville M, Blanche J, et al. HIV-1 DNA levels in peripheral blood mononuclear cells and cannabis use are associated with intermittent HIV shedding in semen of men who have sex with men on successful antiretroviral regimens. Clin Infect Dis 2014;58:1763-70.

26. Cohen MS, Hoffman IF, Royce RA, et al. Reduction of concentration of HIV-1 in semen after treatment of urethritis: implications for prevention of sexual transmission of HIV-1. Lancet 1997;349:1868-73

27. Sadiq ST, Taylor S, Kaye S, et al. The effects of antiretroviral therapy on HIV-1 RNA loads in seminal plasma in HIV-positive patients with and without urethritis. AIDS 2002;16:219-25.

28. Kelley CF, Haaland RE, Patel P, et al. HIV-1 RNA rectal shedding is reduced in men with low plasma HIV-1 RNA viral loads and is not enhanced by sexually transmitted bacterial infections of the rectum. $J$ Infect Dis 2011;204:761-7.

29. Blaschke TF, Osterberg L, Vrijens B, et al. Adherence to medications: insights arising from studies on the unreliable link between prescribed and actual drug dosing histories. Annu Rev Pharmacol Toxicol 2012:52:275-301.

30. Glass TR, Battegay M, Cavassini M, et al. Longitudinal analysis of patterns and predictors of changes in self-reported adherence to antiretroviral therapy: Swiss HIV cohort study. J Acquir Immune Defic Syndr 2010;54:197-203.

31. Katz MH, Schwarcz SK, Kellogg TA, et al. Impact of highly active antiretroviral treatment on HIV seroincidence among men who have sex with men: San Francisco. Am J Public Health 2002;92:388-94.

32. Crepaz N, Hart TA, Marks G. Highly active antiretroviral therapy and sexual risk behaviour: a meta-analytic review. JAMA 2004;292:224-36

33. Writing Group, Williams I, Churchill D, Anderson J, et al. British HIVAssociation. British HIV Association guidelines for the treatment of HIV-1-positive adults with antiretroviral therapy 2012 (updated November 2013). HIV Med 2014;15 Suppl 1:1-85.

34. Montaner J, editor. Therapeutic guidelines for antiretroviral $(A R V)$ treatment of adult HIV infection. Vancouver: British Columbia Centre for Excellence in HIV/AIDS; 2015. Available: www.cfenet.ubc.ca/sites/default/files/uploads/Guidelines/bc-cfe -art-guidelines-Oct 14 2015.pdf (accessed 2015 Dec. 10).

35. Centers for Disease Control and Prevention; Health Resources and Services Administration; National Institutes of Health; American Academy of HIV Medicine; Association of Nurses in AIDS Care; International Association of Providers of AIDS Care; National Minority AIDS Council; Urban Coalition for HIV/AIDS Prevention Services; National Center for HIV/AIDS, Viral Hepatitis, STD, and TB Prevention, Division of HIV/AIDS Prevention. Recommendations for HIV prevention with adults and adolescents with HIV in the United States. Atlanta: Centers for Disease Control and Prevention; 2014. Available: http://stacks.cdc.gov/view/ cdc/26062 (accessed 2015 May 5).

36. Vernazza P, Hirschel B, Bernasconi E, et al. Swiss Commission statement. Commission fédérale pour les problèmes liés au sida (Swiss National AIDS Commission); 2008. Available: www. edwinjbernard.com/pdfs/Swiss\%20Commission\%20statement May\%202008 translation\%20EN.pdf (accessed 2014 Jan. 4).

37. Günthard HF, Aberg JA, Eron JJ, et al. Antiretroviral treatment of adult HIV infection: 2014 recommendations of the International Antiviral Society — USA Panel. JAMA 2014;312:410-25.

38. Panel on Antiretroviral Guidelines for Adults and Adolescents. Guidelines for the use of antiretroviral agents in HIV-1-infected adults and adolescents. Washington: US Department of Health and Human Services; 2015. Available: aidsinfo.nih.gov/contentfiles/ lvguidelines/adultandadolescentgl.pdf (accessed 2015 May 5)

39. Consolidated guidelines on the use of antiretroviral drugs for treating and preventing HIV infection. Recommendations for a public health approach. Geneva: World Health Organization; 2013. Available: www.who.int/hiv/pub/guidelines/arv2013/en/ (accessed 2015 May 5)

Affiliations: School of Nursing, Faculty of Health Sciences (O’Byrne), University of Ottawa, Ottawa, Ont.; Division of Infectious Diseases (MacPherson), Ottawa Hospital, Ottawa, Ont.

Contributors: Both of the authors contributed substantially to the conception and design of the article, to the analysis and interpretation of the reviewed literature, and to the drafting and revision of the manuscript, and both gave final approval of the version to be published and agreed to act as guarantors of the work. 